\title{
Orthognathic surgery for patients with idiopathic condylar resorption: Clinical research
}

\author{
Jeong-Kui Ku' ${ }^{1}$ Nam-Ki Lee ${ }^{2}$ and Young-Kyun Kim ${ }^{1,3 *}$ \\ ${ }^{1}$ Department of Oral and Maxillofacial Surgery, Section of Dentistry, Seoul National University Bundang Hospital, Korea \\ ${ }^{2}$ Department of Orthodontics, Section of Dentistry, Seoul National University Bundang Hospital, Korea \\ ${ }^{3}$ Department of Dentistry \& Dental Research Institute, School of Dentistry, Seoul National University, Korea
}

\begin{abstract}
The objective of this study was to evaluate the rates of relapse, temporomandibular joint (TMJ) changes or disease, and recurrence of idiopathic condylar resorption (ICR) and open bite following orthognathic surgery in patients with ICR. Six Class II patients (aged 19 51) who suffered from ICR and received orthognathic surgery on maxilla and mandible were evaluated. All 6 patients received Le Fort I osteotomy on maxilla. 5 patients received BSSRO with advanced genioplasty and fixation with Miniplate and 1 patient received Obwegeser-Dal Pont's method and fixation with APIS plate on mandible. Lateral cephalograms were taken at presurgical (T0), immediately post-surgical (T1) and 3 months post-surgical (T2), and 6 months post-surgical (T3) stages, and skeletal changes were analyzed with V-Ceph (CyberMed, Seoul, Korea) software. Age and sex, surgery method, fixation material, and post-operative complications of each patient were examined. Only one patient showed TMJ muscle-related disorder symptoms. Open bite recurrence was not observed in any of the 6 patients. Orthognathic surgery on maxilla and mandible shows no relationship with a recurrence of ICR or open bite.
\end{abstract}

\section{Introduction}

Mandibular condylar resorption was first reported by Burke in 1961, who described it as "condylar hypoplasia [1]." Mandibular condylar resorption was differentiated from congenital condylar hypoplasia or aplasia, and the destructive patterns of condylar resorption were reported [2].

Idiopathic condylar resorption (ICR) is characterized by a loss of condylar height, changes in condylar volume and shape, facial changes, and occlusal changes that occur regardless of the patient's history of injury or history of disorders associated with the temporomandibular joint (TMJ). ICR has the following characteristics: (1) It commonly occurs among women aged 15-35 years. (2) It is estimated to occur more among teenage girls during periods of peak growth. (3) It generally affects both condyles. (4) ICR often occurs spontaneously rather than due to injury or other causes. (5) The onset of ICR may be associated with dental prosthetic treatment, orthodontic treatment, and surgery. (6) Discomfort in the MJ and muscular hyperactivity may be observed during the period of active resorption. (7) Changes in the condylar shape (flattening, thinning) may be observed. (8) The condylar height and the vertical length of the face both experience an overall decrease. (9) Angle Class II and an anterior open bite may be observed, according to the magnitude of posterior mandibular displacement [3].

Patients with ICR exhibit abnormal skeletal morphology and distortion of soft tissues adapted to this morphology, which together result in unaesthetic facial patterns. The only way to fix the distortion of the soft tissues around the lips, cheek, and neck is to correct the patient's abnormal skeletal morphology. Therefore, to correct inadequate facial patterns, surgical repositioning of the maxilla (Le fort I), the mandible (Ramus osteotomies), and the tip of the chin (oblique osteotomy) may be necessary.
In addition, mandibular condylar resorption has been reported to be an important cause of skeletal relapse following orthognathic surgery [4]. However, the pathogenesis or causes of mandibular condylar resorption following orthognathic surgery are not clear. It is believed that the risk for condylar resorption is higher for patients whose mandibles are posteriorly positioned, or those who have an Angle Class II anterior open bite with a large mandibular angle. The pathogenesis of condylar resorption may also be affected by the mechanical force applied to the condyles during surgery, the tension in the soft tissues around the condyle (proportional to the anterior displacement of the mandible), and the condylar pressure or displacement caused by the counterclockwise rotation of bone fragments and intermaxillary fixation. Harris et al. reported that the mandibular angle was rotated by $1 \sim 10^{\circ}$ (mean $5.6^{\circ}$ ) in 17 patients who underwent mandibular advancement surgery through BSSRO [5].

Studies on relapse and TMJ changes in patients with ICR following orthognathic surgery are rare. Teitelbaum et al. proposed four requirements for orthognathic surgery of ICR: 1) orthodontic, radiologic, and morphologic stability for at least 6 months; 2) adequate and sophisticated surgical techniques; 3) consistent treatment for TMJ functions; and 4) a long-term follow-up [6].

Correspondence to: Young-Kyun Kim, Department of Oral and Maxillofacial Surgery, Section of Dentistry, Seoul National University Bundang Hospital, 300 Gumi-dong, Bundang-gu, Seongnam city, Gyunggi-do, Korea, Tel: 82-31-7872780; Fax: 82-31-787-4068; E-mail: kyk0505@snubh.org

Key words: orthognathic surgery, idiopathic condyle resorption, open bite, temporomandibular joint disease

Received: November 20, 2017; Accepted: December 15, 2017; Published: December 19, 2017 
This study was aimed at investigating the patterns of vertical and horizontal relapse, the risk of open bite relapse, TMJ disorder, and ICR for patients with ICR and Grade II malocclusion following two-jaw surgery.

\section{Subjects and methods}

Six patients ( 2 male, 4 female) were included; all were diagnosed with skeletal Class II malocclusion and ICR at the TMJ Clinic in the Department of Oral and Maxillofacial Surgery at the Bundang Seoul National University Hospital, and underwent orthodontic treatment and two-jaw surgery after TMJ treatment. Age, sex, method of surgery, and postoperative fixation type were investigated, and medical and radiographic examinations were performed. Immediately before (T0), immediately after (T1), three months after (T2), and six months after (T3) the orthognathic surgery, lateral cephalograms were obtained, and vertical and horizontal skeletal changes were analyzed using V-Ceph software (CyberMed, Seoul, South Korea).

In this study, idiopathic condylar resorption (ICR) was defined as condylar resorption that occurs in the absence of TMJ injury or disorder, and systemic diseases such as rheumatoid arthritis. Patients who exhibited volume changes, such as loss of cortical bone at the mandibular condylar head, morphological changes (erosion, flattening), and hypoplasia, on radiographs such as TM panorama and $\mathrm{CT}$, had an open bite due to a decrease in the condylar height and the clockwise rotation of the mandible, had symptoms of TMJ disorders, and whose bone scan values were greater than 3.88 were diagnosed with ICR.

Although various criteria are used to define and diagnose anterior open bites, in this study, an open bite was defined as being present when occlusion was not marked on an $40 \mu \mathrm{m}$-thick articulating paper (Accufilm II, Parkell, USA).

The mean length of TMJ disorder treatment prior to orthognathic surgery was 11.59 months (a range of 3.9-25.9 months) for the six patients. The method of treatment used for each patient is shown in Table 1. All six patients wore a stabilization splint before beginning orthodontic treatment, and four of the patients underwent conservative treatment using analgesics and occlusal stabilization devices to treat ICR. The other two patients underwent surgical treatment to treat ICR. One patient underwent a surgery in which the mandible was pushed forward via condylar resection, and the other patient underwent TMJ arthrocentesis using an arthroscope. Orthodontic treatment was begun in preparation of orthognathic surgery after the patients' TMJ symptoms were relieved and after condylar resorption appeared to have stopped progressing on X-rays after two months of follow-up. TMJ disorder relapsed in one patient during orthodontic treatment, and accordingly, anti-adhesive agents were injected once into the TMJ cavity, not to the point of affecting orthodontic treatment. A relapse of TMJ disorder was not observed in the remaining five patients.

We continued to follow up with the patients for a mean period of 6.17 months (a range of 1-24 months) after their symptoms were relieved, and they showed no symptoms of TMJ disorder during this period. Accordingly, orthodontic treatment was begun in preparation for the orthognathic period. The orthodontic treatment took 12.04 months on average (a range of $2.86 \sim 46.13$ months). Next, two-jaw surgery was performed. All six patients underwent Lefort I osteotomy on the maxilla. BSSRO was performed on the mandibles of five patients. For the remaining patient, the Obwegeser-Dalpont's method was performed on the right mandible (Figure 1), and the original Obwegeser method was performed on the left mandible (Figure 2).
Orthodontic treatment was performed during the postoperative period, which lasted 20.5 months on average. During this period, radiographs were obtained every three months, and there was no relapse of ICR symptoms, relapse of open bite, and counterclockwise rotation of the mandible. None of the patients required intensive treatment for symptoms of TMJ disorder. While some patients seldom complained of pain during the follow-up period after orthodontic treatment was completed, their symptoms were relieved by taking precautions and consulting their dentists. Therefore, none of the patients required

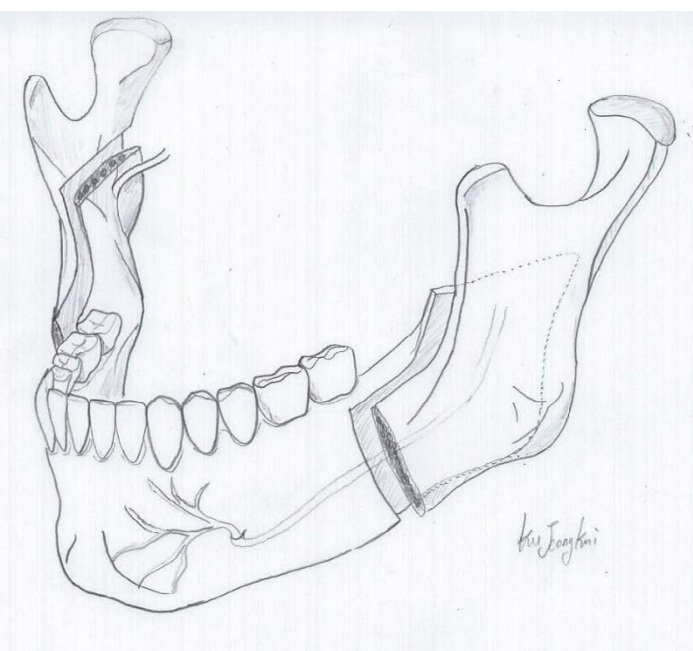

Figure 1. The Obwegeser-Dal pont's method

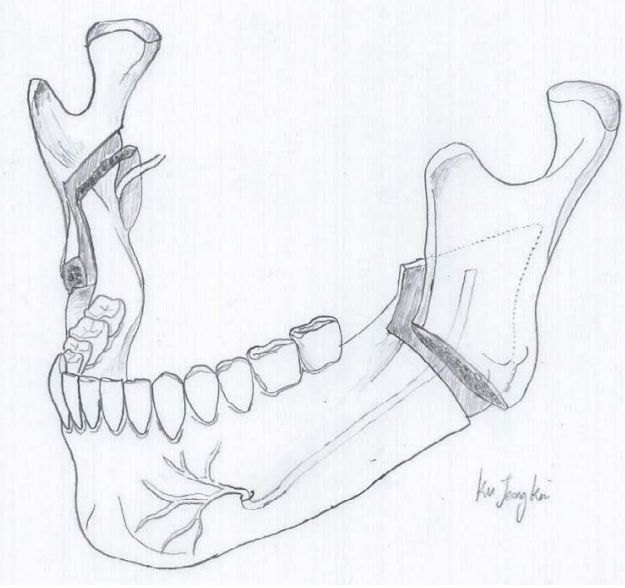

Figure 2. The original Obwegeser method

Table 1. Treatment summary of ICR

\begin{tabular}{|c|c|c|c|c|c|c|}
\hline & Patient & Patient & Patient & Patient & Patient & Patient \\
\cline { 2 - 7 } & No. 1 & No. 2 & No. 3 & No. 4 & No. 5 & No. 6 \\
\hline Stabilization splint & O & O & O & O & O & O \\
\hline Medication:Antidepressants & & & O & & & \\
\hline Medication: NSAID & & O & O & O & O & O \\
\hline Medication: Rheuma gel & & & O & O & & O \\
\hline Laser therapy & & & O & & & O \\
\hline Therabite exercise & & O & & & & \\
\hline TMJ injection: Antiadhesion & & O & O & O & O & \\
\hline TMJ subcondylotomy & & O & & & & \\
\hline TMJ arthocentesis & & & O & & & \\
\hline Treatment period (month) & 6 & 9.7 & 7.63 & 25.9 & 3.8 & 16.53 \\
\hline
\end{tabular}


intensive treatment or had a relapse of ICR symptoms. However, Patient \#2 had a car accident 1 year and 8 months after the orthodontic surgery, which was during the orthodontic treatment follow-up period, and the patient complained of a mouth opening limitation and pain in the left face and TMJ. Anti-adhesive agents were injected accordingly, and laser treatment was performed. The patient did not have a relapse of ICR or experience an open bite thereafter (Table 2).

For relapse assessment following orthognathic treatment, lateral cephalograms were obtained before (T0), immediately after (T1), three months after (T2), and six months after (T3) surgery, and were analyzed using NUSMA for Ceph software (NUSMA ,Seoul, Korea). The cephalograms were measured by a trained orthodontist, and the landmarks and reference line used are shown in Figure 3A. For vertical and horizontal measurements, a reference line such as the one shown in Figure 3B was used, and angles were measured as shown in Figure 3C. Among the landmarks, Pogonion (Pog) and Menton (Me) were selected for assessing the vertical and horizontal positions of the mandible. The horizontal distance was measured as the distance between a line perpendicular to the FH surface that passes through Sella (S) and the corresponding landmark. The vertical distance was measured as the distance between the FH surface and the corresponding landmark. The Ar-pog surface, Ar-Me surface, and mandibular surface were selected to analyze rotational changes in the mandible. Angles between the FH surface and the selected surfaces were measured and analyzed.

To assess surgical changes (T1-T0) and relapses (T2-T1, T3-T1), line and angle measurements were analyzed by a paired t-test. Pearson's correlation coefficients were calculated to assess correlations related to vertical, horizontal, and angular relapse measurements using Pog and $\mathrm{M}$.

\section{Results}

1. Assessment of surgical changes (T1-T0), and horizontal and vertical relapse (T2-T1) using Pog and Me

Table 2. Patients summaries from initial TMJ treatment to end of orthodontic treatment

\begin{tabular}{|c|c|c|c|c|c|c|c|}
\hline & Patient No.1 & \multicolumn{2}{|c|}{$\begin{array}{c}\text { Patient } \\
\text { No.2 }\end{array}$} & Patient No.3 & Patient No.4 & Patient No.5 & Patient No.6 \\
\hline Orthodontic treatment period before surgery & 5.9 & \multicolumn{2}{|c|}{5.57} & 3.77 & 46.13 & 2.87 & 13.93 \\
\hline \multicolumn{8}{|c|}{ Maxilla } \\
\hline Surgery method & Le fort I & \multicolumn{2}{|c|}{ Le fort I } & Le fort I & Le fort I & Le fort I & Le fort I \\
\hline Vertical reduction $(\mathrm{mm})$ & 3 & \multicolumn{2}{|c|}{4} & & 3 & 2 & 2 \\
\hline Horizontal setback & & & & 5 & 2 & 2 & 3 \\
\hline \multicolumn{8}{|c|}{ Mandible } \\
\hline \multirow[b]{2}{*}{ Surgery Method } & \multirow[b]{2}{*}{ BSSRO } & Right & Left & \multirow[b]{2}{*}{ BSSRO } & \multirow[b]{2}{*}{ BSSRO } & \multirow[b]{2}{*}{ BSSRO } & \multirow[b]{2}{*}{ BSSRO } \\
\hline & & $\begin{array}{l}\text { Obwegeser- } \\
\text { Dalpont's } \\
\text { method }\end{array}$ & $\begin{array}{l}\text { Original Obsegeser } \\
\text { method }\end{array}$ & & & & \\
\hline Vertical reduction $(\mathrm{mm})$ & 3 & \multicolumn{2}{|c|}{5} & & 2 & & 3 \\
\hline Horizontal setback & Auto-rotation & & & 4 & 2 & 2.5 & \\
\hline \multicolumn{8}{|c|}{ Genioplasty } \\
\hline Advance (mm) & 5 & & & 4 & 6 & 5 & 4 \\
\hline Fixation material & APIS & \multicolumn{2}{|c|}{ Miniplate } & APIS & APIS & APIS & APIS \\
\hline Orthodontic treatment period until finishing (month) & 24 & \multicolumn{2}{|r|}{9} & 30 & 18 & 24 & 18 \\
\hline TMJ pain occur & $\mathrm{x}$ & \multicolumn{2}{|r|}{ o } & o & o & $\mathrm{X}$ & o \\
\hline Onset (month) & & \multicolumn{2}{|r|}{24} & 2 & 2 & & 0.5 \\
\hline Duration (month) & & \multicolumn{2}{|r|}{3} & 0.5 & 1 & & 2 \\
\hline TMJ Locking & $\mathrm{x}$ & & $\mathrm{x}$ & $\mathrm{x}$ & $\mathrm{x}$ & $\mathrm{x}$ & $\mathrm{x}$ \\
\hline TMJ treatment & $\mathrm{x}$ & Anti-ac & $\begin{array}{l}\mathrm{O} \\
\text { sion injection }\end{array}$ & $\mathrm{x}$ & $\mathrm{x}$ & $\mathrm{x}$ & $\mathrm{x}$ \\
\hline Open bite recurrence & $\mathrm{x}$ & & $\mathrm{x}$ & $\mathrm{x}$ & $\mathrm{x}$ & $\mathrm{x}$ & $\mathrm{x}$ \\
\hline
\end{tabular}
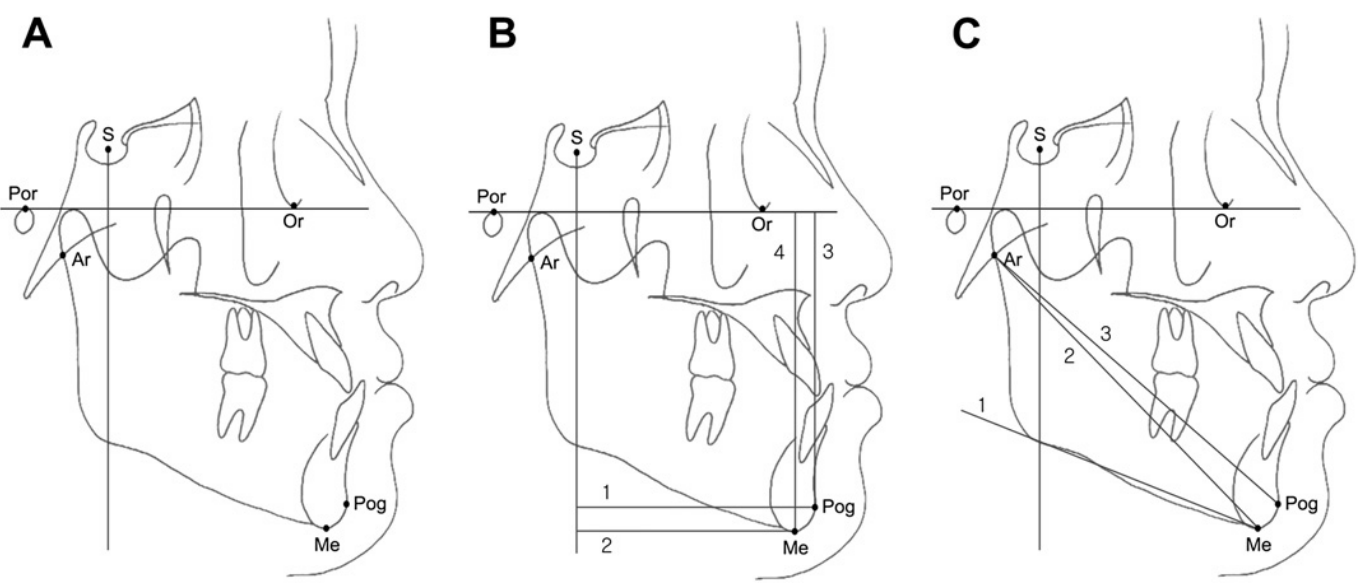

Figure 3. Landmarks, reference planes and measurements for cephalometric analysis.

The landmarks: S means sella; Por, porion; Or, orbitale; Ar, articulare; Me, Menton; Pog, Pogonion. The reference planes: Frankfort horizontal (FH) plane (Or-Por); perpendicular line of S to FH plane (S-perp). (B) The linear measurements (mm): 1, S-perp to Pog; 2, S-perp to Me; 3, FH to Pog; 4, FH to Me. (C) The angular measurements $\left({ }^{\circ}\right)$ : 1 , angle between FH plane and Mandibular plane (FMA), 2, angle between FH plane and Ar-Me (FH to Ar-Me); 3, angle between FH plane and Ar-Pog (FH to Ar-Pog). 
As shown in Table 3 and 4, in the T1-T0 period, the S-perp to Pog, and S-Perp to Me measurements significantly increased, and the Fh to Pog measurement significantly decreased. In both the T2-T1and the T3-T1 periods, the S-perp to Pog, S-Perp to Me, and FH to Me and FH to Pog values significantly decreased.

2. Assessment of surgical changes (T1-T0) and angular relapse (T2T1) using Pog and Me

As shown in Table 5 and 6, the FH to Ar-Pog line, FH to Ar-Me line, and FMA values significantly decreased in the T1-T0 period. No significant changes were observed in the T2-T1 and T3-T1 periods.

3. Correlations with vertical, horizontal and angular relapse in relation to Pog and $\mathrm{Me}$

As shown in Table 7, vertical relapse was correlated with the magnitude of surgical changes to the angle ( $\Delta$ S-perp to Pog T3-T1 and FH to Ar-Pog T0, R=-0.886, $\mathrm{p}<0.05 ; \Delta \mathrm{FH}$ to Ar-Pog T1-T0, R=0.829, $\mathrm{p}<0.05 ; \Delta$ FMA T1-T0, $\mathrm{R}=-1.000, \mathrm{p}<0.001$, S-perp to Pog T0, $\mathrm{R}=0.943$, $\mathrm{p}<0.01$; $\mathrm{S}$-perp to Me T0, R=0.986, $\mathrm{p}<0.01 ; \Delta \mathrm{S}$-perp to Pog T1-T0, R=$0.886, \mathrm{p}<0.05 ; \Delta \mathrm{S}$-perp to Me T1-T0, $\mathrm{R}=-0.886, \mathrm{p}<0.05$, and $\Delta \mathrm{S}$-perp to Me T3-T1 and $\Delta \mathrm{FH}$ to Ar-Me T3-T1, R=-0.943, $<<0.011$ S-perp to Pog T0, $\mathrm{R}=0.886, \mathrm{p}<0.05$; $\mathrm{S}$-prep to Me T0, $\mathrm{R}=0.812$, $\mathrm{p}<0.05 ; \Delta \mathrm{S}$-perp to $\mathrm{Me} \mathrm{T} 2-\mathrm{T} 1, \mathrm{R}=0.812, \mathrm{p}<0.05)$. Vertical relapse was correlated with angular relapse. $(\Delta \mathrm{FH}$ to $\mathrm{Me} \mathrm{T} 3-\mathrm{T} 1$ and $\Delta \mathrm{FH}$ to Ar-Pog T3-T2, R=$.0867, \mathrm{p}<0.05$, and $\Delta \mathrm{FH}$ to $\operatorname{Pog} \mathrm{T} 3-\mathrm{T} 1$ and $\Delta \mathrm{FH}$ to $\operatorname{Pog} \mathrm{T} 3-\mathrm{T} 1, \mathrm{R}=0.938$, $\mathrm{P}<0.01 ; \Delta \mathrm{FH}$ to $\mathrm{Pog} \mathrm{T} 2-\mathrm{T} 1, \mathrm{R}=0.938, \mathrm{p}<0.01)$

\section{Relapse of ICR and open bite}

Before treatment, all six patients had ICR and an open bite caused by counterclockwise rotation of the mandible (Figure 4 ). The patients recovered a normal relationship in the anterior region via appropriate treatment of TMJ disorder accompanied by orthognathic surgery and orthodontic treatment. During follow-up, three patients intermittently complained of having symptoms of TMJ disorder. These symptoms were relieved by taking precautions and consulting their dentists, without the need for special treatment. One patient had a relapse of TMJ disorder due to a head injury and accordingly received an intraarticular injection of anti-adhesive agents. All six patients showed no signs of either a relapse of ICR or an open bite during radiographic and clinical examinations (Figure 5).

\section{Discussion}

Condylar resorption following orthognathic surgery is affected by various surgical and non-surgical factors, and its incidence rate has been reported to vary from 1 to 31\%. In 1994, De Clercq reported an incidence rate of $31 \%$ after observing condylar resorption of greater than $2 \mathrm{~mm}$ in 9 out of 29 female patients who underwent two-jaw surgery [7].

For patients with an anterior open bite, the risk for condylar resorption after orthognathic surgery is higher than in patients with a deep bite. The risk is also nine times greater for women than for men, possibly due to the effects of estrogen and prolactin, which control bone reactions [8].

Table 3. Horizontal and vertical position of Pogonion (Pog) and Menton (Me) in pre-surgical (T0), post-surgical (T1), post-surgical 3 month (T2) and post-retention (T3) stages.

\begin{tabular}{|c|c|c|c|c|c|c|c|c|}
\hline \multirow{2}{*}{ Measurement } & \multicolumn{2}{|c|}{ T0 } & \multicolumn{2}{|c|}{$\mathrm{T} 1$} & \multicolumn{2}{|c|}{$\mathrm{T} 2$} & \multicolumn{2}{|c|}{$\mathrm{T} 3$} \\
\hline & Mean & SD & Mean & SD & Mean & SD & Mean & SD \\
\hline $\begin{array}{l}\text { S-perp to Pog } \\
\text { (mm) }\end{array}$ & 51.3700 & 9.15689 & 59.5200 & 6.55550 & 57.7383 & 7.76250 & 57.3633 & 8.20481 \\
\hline S-Perp to $\mathrm{Me}(\mathrm{mm})$ & 44.1583 & 8.50036 & 52.3433 & 7.02863 & 49.8583 & 8.27957 & 49.8533 & 8.51342 \\
\hline $\mathrm{FH}$ to $\mathrm{Me}(\mathrm{mm})$ & 102.3983 & 3.26377 & 100.4717 & 3.23651 & 99.0950 & 2.87347 & 98.2267 & 2.59859 \\
\hline FH to Pog $(\mathrm{mm})$ & 95.4283 & 2.73208 & 92.0583 & 2.86787 & 91.2400 & 2.51517 & 90.9767 & 3.02901 \\
\hline
\end{tabular}

Table 4. Surgical change (T1-T0) and relapse change (T2-T1, T3-T1) of Pogonion (Pog) and Menton (Me).

\begin{tabular}{|c|c|c|c|c|c|c|c|c|c|}
\hline \multirow{2}{*}{ Measurement } & \multicolumn{3}{|c|}{ T0-T1 } & \multicolumn{3}{|c|}{$\mathrm{T} 1-\mathrm{T} 2$} & \multicolumn{3}{|c|}{ T1-T3 } \\
\hline & Mean & SD & Sig. & Mean & SD & Sig. & Mean & SD & Sig. \\
\hline $\begin{array}{l}\text { S-perp to Pog } \\
\text { (mm) }\end{array}$ & -8.15000 & 3.08352 & .001 & 1.78167 & 1.64871 & .046 & 2.24500 & .77943 & .001 \\
\hline $\begin{array}{l}\text { S-Perp to Me } \\
\quad(\mathrm{mm})\end{array}$ & -8.18500 & 1.87289 & .000 & 2.48500 & 1.75215 & .018 & 1.08167 & 1.91593 & .225 \\
\hline FH to $\mathrm{Me}(\mathrm{mm})$ & 1.92667 & 3.80973 & .270 & 1.37667 & .91769 & .014 & 2.15667 & 1.81555 & .033 \\
\hline FH to $P o g(\mathrm{~mm})$ & 3.37000 & 1.20456 & .001 & .81833 & 1.29392 & .182 & 2.49000 & 1.79854 & .019 \\
\hline
\end{tabular}

Table 5. Angular measurements in pre-surgical (T0), post-surgical 3-month (T2) and post-retention (T3) stages.

\begin{tabular}{|c|c|c|c|c|c|c|c|c|}
\hline \multirow{2}{*}{ Measurement } & \multicolumn{2}{|c|}{ T0 } & \multicolumn{2}{|c|}{$\mathrm{T} 1$} & \multicolumn{2}{|c|}{$\mathrm{T} 2$} & \multicolumn{2}{|c|}{$\mathrm{T} 3$} \\
\hline & Mean & SD & Mean & SD & Mean & SD & Mean & SD \\
\hline $\begin{array}{l}\text { FH to Ar-Pog } \\
\text { line }\left({ }^{\circ}\right)\end{array}$ & 51.5067 & 3.73587 & 47.0383 & 2.99799 & 47.4383 & 3.41504 & 47.4767 & 3.57416 \\
\hline $\begin{array}{c}\mathrm{FH} \text { to } \mathrm{Ar}-\mathrm{Me} \\
\text { line }\left({ }^{\circ}\right)\end{array}$ & 56.8400 & 3.59522 & 52.7267 & 3.62424 & 53.3333 & 3.61937 & 53.0683 & 3.69489 \\
\hline $\operatorname{FMA~}\left({ }^{\circ}\right)$ & 38.0217 & 6.77484 & 33.1683 & 7.55269 & 34.3167 & 7.38698 & 33.9417 & 6.90963 \\
\hline
\end{tabular}

Table 6. Surgical change (T1-T0) and relapse change (T2-T1, T3-T1) of angular measurements.

\begin{tabular}{|c|c|c|c|c|c|c|c|c|c|}
\hline \multirow{2}{*}{ Measurement } & \multicolumn{3}{|c|}{$\mathrm{T} 0-\mathrm{T} 1$} & \multicolumn{3}{|c|}{$\mathrm{T} 1-\mathrm{T} 2$} & \multicolumn{3}{|c|}{ T1-T3 } \\
\hline & Mean & SD & Sig. & Mean & SD & Sig. & Mean & SD & Sig \\
\hline $\begin{array}{c}\text { FH to } \mathrm{Ar}-\mathrm{Pog} \\
\text { line }\left({ }^{\circ}\right)\end{array}$ & 4.46833 & 1.12013 & .000 & -.40000 & .92096 & .336 & -.43833 & .97091 & .319 \\
\hline $\begin{array}{c}\mathrm{FH} \text { to } \mathrm{Ar}-\mathrm{Me} \\
\text { line }\left({ }^{\circ}\right)\end{array}$ & 4.11333 & .79754 & .000 & -.60667 & .79031 & .119 & -.34167 & .96124 & .424 \\
\hline FMA $\left(^{\circ}\right)$ & 4.85333 & 2.40371 & .004 & -1.14833 & 1.74888 & .169 & -.77333 & 1.71115 & .319 \\
\hline
\end{tabular}


Table 7. Pearson's correlation coefficients of horizontal relapse and vertical relapse to other measurements such as pre-surgical (T0) stage, surgical change (T1-T0) and relapse change (T2T1, T3-T1) of horizontal, vertical and angular measurements.

\begin{tabular}{|c|c|c|c|c|c|c|c|c|c|c|}
\hline & \multirow{4}{*}{ Measurement } & & \multicolumn{8}{|c|}{ Relapse Measurements (T3-T1) } \\
\hline & & & \multicolumn{4}{|c|}{ Horizontal distance from S-prep } & \multicolumn{4}{|c|}{ Vertical distance from $\mathrm{FH}$} \\
\hline & & & \multicolumn{2}{|c|}{ Pog } & \multicolumn{2}{|c|}{$\mathrm{Me}$} & \multicolumn{2}{|c|}{ Pog } & \multicolumn{2}{|c|}{$\mathrm{Me}$} \\
\hline & & & $\mathrm{R}^{*}$ & Sig.' & $\mathrm{R}^{*}$ & Sig.' & $\mathrm{R}^{*}$ & Sig.' & $\mathrm{R}^{*}$ & Sig.' \\
\hline \multirow{10}{*}{ Horizontal } & \multirow{5}{*}{ S-perp to Pog (mm) } & $\mathrm{T} 0$ & 0.943 & $* *$ & 0.886 & $*$ & -0.069 & NS & 0.413 & NS \\
\hline & & T1-T0 & -0.886 & $*$ & -0.486 & NS & 0.116 & NS & -0.551 & NS \\
\hline & & $\mathrm{T} 2-\mathrm{T} 1$ & 0.714 & NS & 0.429 & NS & 0.382 & NS & -0.341 & NS \\
\hline & & $\mathrm{T} 3-\mathrm{T} 2$ & 0.714 & NS & 0.714 & NS & 0.458 & NS & 0.789 & \\
\hline & & T3-T1 & & & 0.714 & NS & 0.087 & NS & 0.182 & NS \\
\hline & \multirow{5}{*}{ S-perp to $\mathrm{Me}(\mathrm{mm})$} & T0 & 0.986 & $* *$ & 0.812 & $*$ & -0.114 & NS & 0.317 & NS \\
\hline & & T1-T0 & -0.886 & $*$ & -0.486 & NS & 0.211 & NS & -0.629 & NS \\
\hline & & $\mathrm{T} 2-\mathrm{T} 1$ & 0.696 & NS & 0.812 & $*$ & 0.232 & NS & -0.159 & NS \\
\hline & & $\mathrm{T} 3-\mathrm{T} 2$ & -0.086 & NS & 0.257 & NS & 0.406 & NS & 0.332 & NS \\
\hline & & $\mathrm{T} 3-\mathrm{T} 1$ & 0.714 & NS & & & 0.487 & NS & 0.059 & NS \\
\hline \multirow{10}{*}{ Vertical } & \multirow{5}{*}{ FH to $\operatorname{Pog}(\mathrm{mm})$} & T0 & 0.143 & NS & 0.143 & NS & -0.303 & NS & -0.583 & NS \\
\hline & & T1-T0 & -0.829 & $*$ & -0.371 & NS & 0.099 & NS & -0.7 & NS \\
\hline & & $\mathrm{T} 2-\mathrm{T} 1$ & 0.086 & NS & 0.6 & NS & 0.938 & $* *$ & 0.263 & NS \\
\hline & & T3-T2 & -0.714 & NS & -0.143 & NS & 0.842 & $*$ & -0.46 & \\
\hline & & $\mathrm{T} 3-\mathrm{T} 1$ & -0.371 & NS & 0.257 & NS & & & -0.023 & NS \\
\hline & \multirow{5}{*}{$\mathrm{FH}$ to $\mathrm{Me}(\mathrm{mm})$} & T0 & 0.886 & $*$ & 0.486 & NS & -0.287 & NS & 0.003 & NS \\
\hline & & T1-T0 & -0.771 & NS & -0.257 & NS & 0.446 & NS & -0.731 & NS \\
\hline & & $\mathrm{T} 2-\mathrm{T} 1$ & 0.486 & NS & 0.543 & NS & 0.401 & NS & 0.752 & NS \\
\hline & & $\mathrm{T} 3-\mathrm{T} 2$ & -0.143 & NS & -0.714 & NS & -0.379 & NS & 0.146 & NS \\
\hline & & T3-T1 & 0.29 & NS & 0 & NS & -0.23 & NS & & \\
\hline \multirow{15}{*}{ Angular } & \multirow{5}{*}{ FH to $\operatorname{Ar}-\operatorname{Pog}\left({ }^{\circ}\right)$} & T0 & -0.886 & $*$ & -0.486 & NS & 0.657 & NS & -0.589 & NS \\
\hline & & T1-T0 & 0.829 & $*$ & 0.371 & NS & -0.657 & NS & 0.33 & NS \\
\hline & & $\mathrm{T} 2-\mathrm{T} 1$ & -0.771 & NS & -0.257 & NS & 0.771 & NS & 0.26 & NS \\
\hline & & $\mathrm{T} 3-\mathrm{T} 2$ & -0.6 & NS & -0.486 & NS & -0.2 & NS & -0.867 & $*$ \\
\hline & & T3-T1 & -0.771 & NS & -0.257 & NS & 0.771 & NS & -0.089 & NS \\
\hline & \multirow{5}{*}{$\mathrm{FH}$ to $\mathrm{Ar}-\mathrm{Me}\left({ }^{\circ}\right)$} & T0 & -0.543 & NS & -0.371 & NS & 0.6 & NS & -0.329 & NS \\
\hline & & T1-T0 & 0.143 & NS & 0.429 & NS & 0.029 & NS & -0.458 & NS \\
\hline & & $\mathrm{T} 2-\mathrm{T} 1$ & -0.657 & NS & -0.6 & NS & 0.143 & NS & 0.342 & NS \\
\hline & & $\mathrm{T} 3-\mathrm{T} 2$ & -0.086 & NS & -0.6 & NS & -0.429 & NS & -0.023 & NS \\
\hline & & T3-T1 & -0.543 & NS & -0.943 & $* *$ & -0.371 & NS & 0.267 & NS \\
\hline & \multirow{5}{*}{ FMA $\left(^{\circ}\right)$} & T0 & 0.086 & NS & 0.6 & NS & 0.543 & NS & -0.616 & NS \\
\hline & & T1-T0 & -1 & $* * *$ & -0.714 & NS & 0.371 & NS & -0.294 & NS \\
\hline & & $\mathrm{T} 2-\mathrm{T} 1$ & 0.429 & NS & 0.429 & NS & 0.143 & NS & 0.506 & NS \\
\hline & & T3-T2 & 0.029 & NS & -0.657 & NS & -0.6 & NS & 0.411 & NS \\
\hline & & T3-T1 & 0.486 & NS & 0.257 & NS & -0.143 & NS & 0.701 & NS \\
\hline
\end{tabular}

For two years, Brostlap et al. monitored 222 patients who underwent BSSRO, and they observed condylar resorption in $4 \%$ of these patients. Most (77\%) of the patients who showed condylar resorption had developed condylar resorption within 6-24 months of surgery [9].

In this case report, all patients, with an exception of one patient, were followed up for over two years, with the shortest follow-up being 14 months long. The patient who was followed up for 14 months did not exhibit any symptoms that were suggestive of condylar resorption, but should still be monitored consistently in the future.

Orthodontic treatment alone can also induce condylar resorption, although the correlation between the two is not clear. A shortened ramus of the mandible, mandibular rotation in the posteroinferior direction, and severe condylar resorption may be observed on lateral cephalograms. Peltola et al. reported flattened mandibular condyles in $9 \%$ of 625 patients who underwent orthodontic treatment [10].

Another study has reported that for patients with IRC, orthognathic surgery should be performed after observing that the patients do not exhibit any clinical, radiological, or orthognathic symptoms for at least six months [6]. It has also been reported that in order to prevent condylar resorption after orthognathic surgery, it is important to prevent unnecessary pressure on the condyle and three-dimensional positional changes $[4,11]$.

The definition of anterior open bite varies from author to author. Some define it as the state in which the anterior teeth of the mandible are not covered by the anterior teeth of the maxilla in a vertical relationship [12]. Others define it as the state in which the cross-section of the occlusal surface is separate, and the occlusal surfaces of the maxilla and mandible do not overlap [13]. An open bite tends to recur after treatment. According to a study by Denision et al., two-jaw surgery has low rates of open bite relapse and creates a more harmonious face [14]. However, because open bite relapse is the result of various factors, including tongue position, breathing habits, and the habit of sticking the tongue out [15], it is difficult to determine if an open bite relapse was due to skeletal instability or orthodontic causes. In addition, the most drastic changes occur in the first eight weeks following orthognathic surgery, during which period a relapse frequently occurs [16]. However, because various factors affect postoperative changes, long-term follow-up is necessary [17]. 


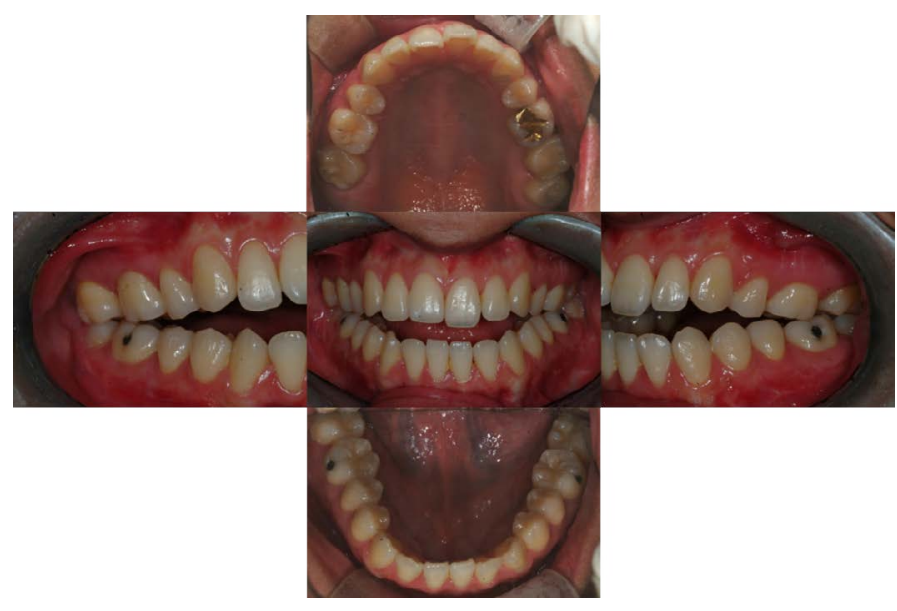

Figure 4. Initial intra-oral photo: Anterior open bite was observed

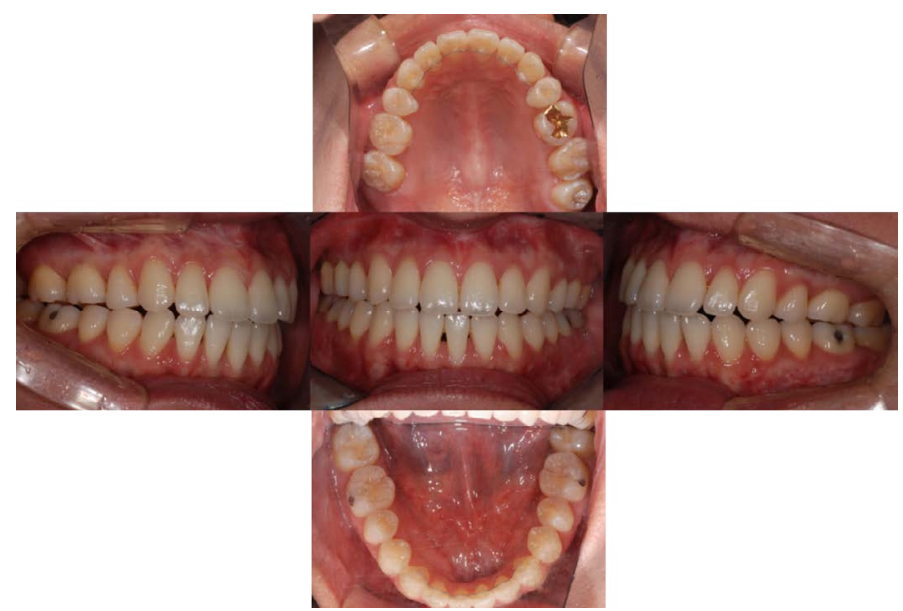

Figure 5. Final intra-oral photo: 23.27 months after orthognathic surgery. There is no open bite recurrence.

In this case report, symptoms associated with the TMJ were not associated with the timing of orthodontic treatment, and the timing of orthognathic surgery was also not associated with postoperative TMJ symptoms or open bite relapse in patients with TMJ disorder. The period of orthodontic preparation prior to orthognathic surgery was less than six months for four of the total six patients (Patient $1=5$ months, Patient $2=7$ months, Patient $3=5$ months, Patient $4=12$ months, Patient $5=1.5$ months, Patient $6=6$ months); in other words, these patients underwent orthognathic surgery with minimal orthodontic preparation (OSMO) [11]. The length of orthodontic preparation was not associated with TMJ symptoms or open bite relapse or worsening. However, while all patients showed Class II malocclusion and signs of an open bite, the results of the statistical analysis of relapse tendencies were rather inconsistent [18]. This may be due to different directions of bone fragment displacement and surgical methods, which made it difficult to obtain data that would allow for an objective assessment of relapse tendencies. Because there has not been any detailed study on OSMO of the maxilla and mandible of patients with Class II malocclusion, it was difficult to make any comparison on skeletal relapse rates.

One patient in this case report underwent both orthodontic treatment when TMJ symptoms had not improved, as well as TMJ treatment upon symptoms worsening. The patient showed improvements in TMJ symptoms following orthognathic surgery. This may have been possible because the surgeon had a full understanding of both the pressure that would be applied to the condyle and the three-dimensional positional changes, and was therefore able to apply sophisticated and accurate surgical techniques at the time of the surgery.

Based on the findings of this case report, it appears that ICR is not associated with condylar resorption or worsening of an open bite after orthognathic surgery. However, additional long-term research using a larger number of patients is necessary to confirm this result. Twojaw surgery, at least when accompanied by orthodontic treatment, was not associated with the relapse of ICR or an open bite in patients with ICR. In the case of TMJ disorder, which is difficult to treat, patients may experience TMJ symptom relief following orthognathic surgery; however, this is only the case if the surgeon has a full understanding of mandibular condyles and can use sophisticated surgical techniques. Long-term statistical research on complications and relapse after condylar resorption and orthognathic surgery must be conducted using a larger number of patients.

\section{References}

1. Burke PH (1961) A case of acquired unilateral mandibular condylar hypoplasia. Proc $R$ Soc Med 54: 507-510. [Crossref]

2. Rabey GP (1977) Bilateral mandibular condylysis-a morphanalytic diagnosis. $\mathrm{Br} J$ Oral Surg 15: 121-134. [Crossref]

3. Posnick JC, Fantuzzo JJ (2007) Idiopathic Condylar Resorption: Current Clinical Perspectives. J Oral Maxillofac Surg 65: 1617-1623. [Crossref]

4. Catherine Z, Breton P, Bouletreau P (2016) Condylar resorption after orthognathic surgery: A systematic review. Rev Stomatol Chir Maxillofac Chir Orale 117: 3-10. [Crossref]

5. Harris MD, Van Sickels JE, Alder M (1999) Factors influencing condylar position after the bilateral sagittal split osteotomy fixed with bicortical screws. J Oral Maxillofac Surg 57: 650-654. [Crossref]

6. Teitelbaum J, Bouletreau P, Breton P, Freidel M (2007) Is condylar resorption a contraindication for surgery?. Rev Stomatol Chir Maxillofac 108: 193-200. [Crossref]

7. De Clercq CA, Neyt LF, Mommaerts MY, Abeloos JV, De Mot BM (1994) Condylar resorption in orthognathic surgery: a retrospective study. Int $J$ Adult Orthodon Orthognath Surg 9: 233-240. [Crossref]

8. Kerstens HC, Tuinzing DB, Golding RP, van der Kwast WA (1990) Condylar atrophy and osteoarthrosis after bimaxillary surgery. Oral Surg Oral Med Oral Pathol 69: 274 280. [Crossref]

9. Borstlap WA, Stoelinga PJ, Hoppenreijs TJ, van't Hof MA (2004) Stabilisation of sagittal split advancement osteotomies with miniplates: a prospective, multicentre study with two-year follow-up: Part III. Condylar remodelling and resorption. Int $J$ Oral Maxillofac Surg 33: 649-655. [Crossref]

10. Peltola JS, Nyström M, Könönen M, Wolf J (1995) Radiographic structural findings in the mandibular condyles of young individuals receiving orthodontic treatment. Acta Odontol Scand 53: 85-91. [Crossref]

11. Lee NK, Kim YK, Yun PY, Kim JW (2013) Evaluation of post-surgical relapse after mandibular setback surgery with minimal orthodontic preparation. J Craniomaxillofac Surg 41: 47-51. [Crossref]

12. Kim YK (2017) Complications associated with orthognathic surgery. J Korean Assoc Oral Maxillofac Surg 43: 3-15. [Crossref]

13. Kim YH (1987) Anterior Openbite malocclusion; nature, diagnosis and treatment by means of Multiloop Edgewise Archwire Technique. Angle Orthod 57: 290-321. [Crossref]

14. Miguel JA, Turvey AT, Phillips C, Proffit WR (1995) Long-term stability of two-jaw surgery for treatment of mandibular deficiency and vertical maxillary excess. Int $J$ Adult Orthodon Orthognath Surg 10: 235-245. [Crossref]

15. Vaezi T, Zarch SHH, Eshghpour M, Kermani H (2017) Two-dimensional and volumetric airway changes after bimaxillary surgery for class III malocclusion. J Korean Assoc Oral Maxillofac Surg 43: 88-93. [Crossref]

16. Kahnberg KE, Zouloumis L, Widmark G (1994) Correction of open bite by maxillary osteotomy. A comparison between bone plate and wire fixation. $J$ Craniomaxillofac Surg 22: 250-255. 
17. Chang YI, Moon SC (1998) The Diagnosis and Treatment of Anterior Openbite Malocclusion. Korean J Orhod 28: 893-904.
18. Kim YK, Kim YJ, Yun PY, Kim JW (2009) Evaluation of skeletal and surgical factors related to relapse of mandibular setback surgery using the bioabsorbable plate. $J$ Craniomaxillofac Surg 37: 63-38. [Crossref]

Copyright: (C2017 Ku JK. This is an open-access article distributed under the terms of the Creative Commons Attribution License, which permits unrestricted use, distribution, and reproduction in any medium, provided the original author and source are credited. 